\title{
Comment on Kim et al. The Association between Coffee Consumption and Risk of Colorectal Cancer in a Korean Population. Nutrients 2021, 13, 2753
}

\author{
Ravi Dhawan ${ }^{1,+}\left(\mathbb{D}\right.$, Yuchen Zhao ${ }^{1,+} \mathbb{\infty}$, Edward Giovannucci ${ }^{1,2, *}$ and Stephanie Smith-Warner ${ }^{1,2, *}$ \\ 1 Department of Epidemiology, Harvard T.H. Chan School of Public Health, Boston, MA 02115, USA; \\ ravidhawan@hsph.harvard.edu (R.D.); yuchenzhao@hsph.harvard.edu (Y.Z.) \\ 2 Department of Nutrition, Harvard T.H. Chan School of Public Health, Boston, MA 02215, USA \\ * Correspondence: egiovann@hsph.harvard.edu (E.G.); swarner@hsph.harvard.edu (S.S.-W.); \\ Tel.: +1-(617)-432-4648 (E.G.); +1-(617)-432-4977 (S.S.-W.) \\ + These authors contributed equally to this work.
}

check for updates

Citation: Dhawan, R.; Zhao, Y.; Giovannucci, E.; Smith-Warner, S. Comment on Kim et al. The Association between Coffee Consumption and Risk of Colorectal Cancer in a Korean Population. Nutrients 2021, 13, 2753. Nutrients 2021, 13, 4514. https://doi.org/ $10.3390 /$ nu13124514

Academic Editor: Marilyn Cornelis

Received: 5 November 2021

Accepted: 14 December 2021

Published: 17 December 2021

Publisher's Note: MDPI stays neutral with regard to jurisdictional claims in published maps and institutional affiliations.

Copyright: (c) 2021 by the authors. Licensee MDPI, Basel, Switzerland. This article is an open access article distributed under the terms and conditions of the Creative Commons Attribution (CC BY) license (https:// creativecommons.org/licenses/by/ $4.0 /)$.
We read with interest the recent publication in Nutrients by Kim et al. [1] on the association between coffee consumption and odds of developing colorectal cancer (CRC) in a Korean population after adjustment for consumption of coffee additives. The authors offered insights on the potential protective effects of coffee consumption on CRC risk, but the study had limitations regarding its study design and data analysis that deserve comment.

To the best of our knowledge, no prior cohort or case-control studies have assessed the protective effects of coffee consumption on CRC in a Korean population [2,3]. In this novel study by Kim et al., no appreciable association was observed in the analysis after adjusting for age, sex, education, occupation, smoking, alcohol, total energy intake, physical activity, BMI, and first-degree family history of CRC in every analysis among women and men combined, by sex, or by tumor site (Model 2). However, after further adjustment for coffee additives (Model 3), the odds ratio (OR) for the risk of developing CRC among those drinking $\geq 3$ cups of coffee/day compared to non-coffee drinkers decreased approximately two- to three-fold. For instance, the observed OR for CRC diagnosis among $\geq 3$ cups/day drinkers vs. non-drinkers changed from 0.71 in the unadjusted model (Model 1) to 0.68 in the adjusted model (Model 2) to 0.22 after further adjustment for coffee additive use (Model 3). These results suggest strong protective effects of coffee consumption on CRC risk; however, this inverse association only emerged after further adjustment for cream and sugar additives. The authors correctly identified coffee additives as potential confounders. For example, it is plausible that the consumption of sugary beverages, especially early in life, may be associated with increased CRC risk [4,5]. Moreover, studies suggest that over $80 \%$ of the total coffee market in Korea consists of instant coffee mixes that contain sugar and cream additives [6,7]. From Table 1 [1], coffee additives intake increased linearly with coffee intake. The authors stated there was not a multicollinearity issue in their analyses. We are interested in how this was assessed as we question whether the independent effects of coffee and additives in this population can be teased statistically by simultaneous modeling. We recommend comparing coffee drinkers with high additive intake and separately coffee drinkers with low additive intake with non-drinkers of coffee, which will avoid potential collinearity. The present analysis may be limited by few high coffee drinkers with low additives, but it may provide a realistic perspective of the data in attempting to separate their effects.

We commend the authors for recognizing the potential confounding by additives and encourage the further exploration of analytic methods to clarify the impact of coffee additives on the coffee and CRC association. 
Author Contributions: Conceptualization, R.D. and Y.Z.; writing—original draft preparation, R.D. and Y.Z.; writing-review and editing, R.D., Y.Z., E.G. and S.S.-W.; supervision, E.G. and S.S.-W.; project administration, E.G. and S.S.-W. All authors have read and agreed to the published version of the manuscript.

Funding: This research received no external funding.

Institutional Review Board Statement: Not applicable.

Informed Consent Statement: Not applicable.

Data Availability Statement: Not applicable.

Conflicts of Interest: The authors declare no conflict of interests.

\section{References}

1. Kim, Y.; Lee, J.; Oh, J.H.; Chang, H.J.; Sohn, D.K.; Shin, A.; Kim, J. The Association between Coffee Consumption and Risk of Colorectal Cancer in a Korean Population. Nutrients 2021, 13, 2753. [CrossRef] [PubMed]

2. World Cancer Research Fund/American Institute for Cancer Research. Diet, Nutrition, Physical Activity and Cancer: A Global Perspective; Continuous Update Project Expert Report; WCRF International: London, UK, 2018. Available online: https: / www. wcrf.org/wp-content/uploads/2021/02/colorectal-cancer-slr.pdf (accessed on 2 November 2021).

3. Colorectal Cancer-WCRF International. Available online: https://www.wcrf.org/dietandcancer/colorectal-cancer/ (accessed on 2 November 2021).

4. Tayyem, R.F.; Bawadi, H.A.; Shehadah, I.; Bani-Hani, K.E.; Takruri, H.; Al-Jaberi, T.; Heath, D.D. Fast Foods, Sweets and Beverage Consumption and Risk of Colorectal Cancer: A Case-Control Study in Jordan. Asian Pac. J. Cancer Prev. 2018, 19, 261-269. [PubMed]

5. Zhang, X.-F.; Wang, X.-K.; Tang, Y.-J.; Guan, X.-X.; Guo, Y.; Fan, J.-M.; Cui, L.-L. Association of Whole Grains Intake and the Risk of Digestive Tract Cancer: A Systematic Review and Meta-Analysis. Nutr. J. 2020, 19, 52. [CrossRef] [PubMed]

6. Lee, J.; Kim, H.-Y.; Kim, J. Coffee Consumption and the Risk of Obesity in Korean Women. Nutrients 2017, 9, 1340. [CrossRef] [PubMed]

7. Kim, Y.; Le, Y. Moderate coffee consumption is inversely associated with the metabolic syndrome in the Korean adult population. Br. J. Nutr. 2018, 120, 1279-1287. [CrossRef] [PubMed] 